\title{
Surgical techniques for the treatment of ankyloglossia in children: a case series
}

\begin{abstract}
Marina Azevedo JUNQUEIRA, Nayara Nery Oliveira CUNHA, Lidiane Lucas Costa e SILVA, Leandro Borges ARAÚJO, Ana Beatriz Silveira MORETTI, Carlos Eduardo Gomes COUTO FILHO, Vivien Thiemy SAKA
\end{abstract}

Department of Clinics and Surgery, School of Dentistry, Federal University of Alfenas, Alfenas, MG, Brazil.

Corresponding address: Vivien Thiemy Sakai - School of Dentistry, Federal University of Alfenas - Rua Gabriel Monteiro da Silva, 700 - Alfenas-MG - Brazil - 37130-000 - Phone \#: 553532991425 - Fax \#: 553532991063 - e-mail: vivien.sakai@unifal-mg.edu.br

Submitted: November 19, 2013 - Modification: December 13, 2013 - Accepted: January 15, 2014

\section{ABSTRACT}

\begin{abstract}
$T^{n}$ his paper reports a series of clinical cases of ankyloglossia in children, which were approached by different techniques: frenotomy and frenectomy with the use of one hemostat, two hemostats, a groove director or laser. Information on the indications, contraindications, advantages and disadvantages of the techniques was also presented. Children diagnosed with ankyloglossia were subjected to different surgical procedures. The choice of the techniques was based on the age of the patient, length of the frenulum and availability of the instruments and equipment. All the techniques presented are successful for the treatment of ankyloglossia and require a skilled professional. Laser may be considered a simple and safe alternative for children while reducing the amount of local anesthetics needed, the bleeding and the chances of infection, swelling and discomfort.
\end{abstract}

Keywords: Frenectomy. Frenotomy. Lingual frenum. Oral surgery. Tongue-tie.

\section{INTRODUCTION}

Ankyloglossia, also known as tongue-tie, is a congenital anomaly characterized by an abnormally short lingual frenulum ${ }^{25}$. Its prevalence is around $4.4 \%$ to $4.8 \%$ in newborns, with a male to female ratio of $3: 1 \cdot 0^{6,10,25}$. Clinically, the term has been used to describe different situations, such as a tongue that is fused to the floor of the mouth as well as a tongue with impaired mobility due to a short and thick lingual frenulum ${ }^{31}$.

There is continuing controversy over the diagnostic criteria and treatment of ankyloglossia ${ }^{26}$. Several studies establish diagnostic criteria based on the length of the lingual frenulum ${ }^{7}$, amplitude of tongue movement ${ }^{5,11,14,23}$, heart-shaped look when the tongue is protruded and thickness of the fibrous membrane ${ }^{2,9,12}$. In children, ankyloglossia can lead to breastfeeding difficulties, speech disorders, poor oral hygiene and bullying during childhood and adolescence $^{30}$.

During the $18^{\text {th }}$ century, midwives used to divide the lingual frenulum with their sharp fingernails ${ }^{10,13}$. For over a century, a grooved tablespoon was created specifically to release the tongue-ties ${ }^{10,20}$. Pediatricians used similar devices over decades, but recurrence was common. Nowadays, several surgical techniques have been described to correct an abnormal frenulum $1,2,10,12,22,29$. The following techniques are of particular interest in Pediatric Dentistry: frenotomy and frenectomy with the use of one hemostat, two hemostats, a groove director or laser.

Therefore, the purpose of the present article was to describe a series of clinical cases of ankyloglossia, which were approached by various techniques. Additionally, information on the indications, contraindications, advantages and disadvantages of the techniques was presented.

\section{CASE REPORTS}

\section{Frenotomy}

A two-year-old boy with ankyloglossia was referred to the Clinic of Pediatric Dentistry for management of the oral condition due to speech delay. Intraoral clinical examination showed a heart-shaped tongue during protrusion and a short lingual frenulum with anterior insertion (Fig. 1A). After extraoral and intraoral antisepsis with $2 \%$ and $0.12 \%$ chlorhexidine, respectively, topical local anesthesia was achieved by application of 
a eutectic mixture of $2.5 \%$ lidocaine and $2.5 \%$ prilocaine $\left(E M L A^{\circledR}\right)$ for 5 minutes. The frenulum was cut with Goldman Fox scissors, in a single motion, by holding the tongue up towards the palate (Fig. 1B) and cutting through the white, fascia-like tissue along a line parallel with the tongue (Fig. 1C). No suture was needed.

Frenectomy with the use of one hemostat

An eight-year-old female with ankyloglossia was referred from a speech therapist to undergo frenectomy due to restriction of tongue movement and function. Clinically, the patient presented a thick and short lingual frenulum with anterior insertion (Fig. 2A and B). After antisepsis, the bilateral lingual nerve blocks and local infiltration in the anterior area were performed with $2 \%$ lidocaine with 1:100,000 epinephrine. A 3-0 silk suture on the tip of the tongue was used for traction. The frenulum was held with a small curved hemostat with the convex curve facing the ventral surface of the tongue (Fig. 2C). The first incision was made with a \#15c blade following the curvature of the hemostat, cutting through the upper aspect of the frenulum (Fig. 2D). The second incision was made at the lower aspect of the frenulum, fairly close to the floor of the mouth (Fig. 2E). The frenulum was then excised, leaving a diamond-shaped wound. The wound margins were undermined with the tips of blunt-ended dissecting scissors (Fig. 2F). Tensionfree closure was checked through the insertion of the first absorbable 5-0 vicryl suture at the middle of the wound. Additional sutures were placed along the tongue base and on the floor of the mouth (Fig. $2 \mathrm{G})$. The postoperative period was uneventful and the remaining sutures were removed after 7 days (Fig. 2E).

\section{Frenectomy with the use of two hemostats}

An eight-year-old male who felt socially embarrassed about his tongue-tie presented for treatment. Clinical examination revealed a short and thick lingual frenulum, thus lingual frenectomy was indicated (Fig. 3A and B). The antisepsis, anesthesia and tongue traction were conducted as previously described. After achieving good anesthesia, two hemostats (one curved and the other straight) were placed against the tissues over the superior and inferior aspects of the frenulum, respectively, with their tips meeting in the deep aspect near the base of the tongue (Fig. 3C). Two incisions were made with a \#15c blade following the hemostats, cutting through the upper and lower aspects of the frenulum, thus a triangular tissue held with the hemostats was completely removed (Fig. 3D). Fiber remnants were excised (Fig. 3E), blunt dissection was performed and 3-0 silk sutures were placed over the wound (Fig. 3F). After the surgery, the patient was referred to a speech therapist.

\section{Frenectomy with the use of a grooved director}

An eleven-year-old female was referred to the Clinic of Pediatric Dentistry for assessment of the lingual frenulum. The clinical examination revealed a heart-shaped, short lingual frenulum with apical insertion (Fig. 4A and B). After antisepsis and anesthesia, the tongue was raised toward the palate with a grooved director and an incision was
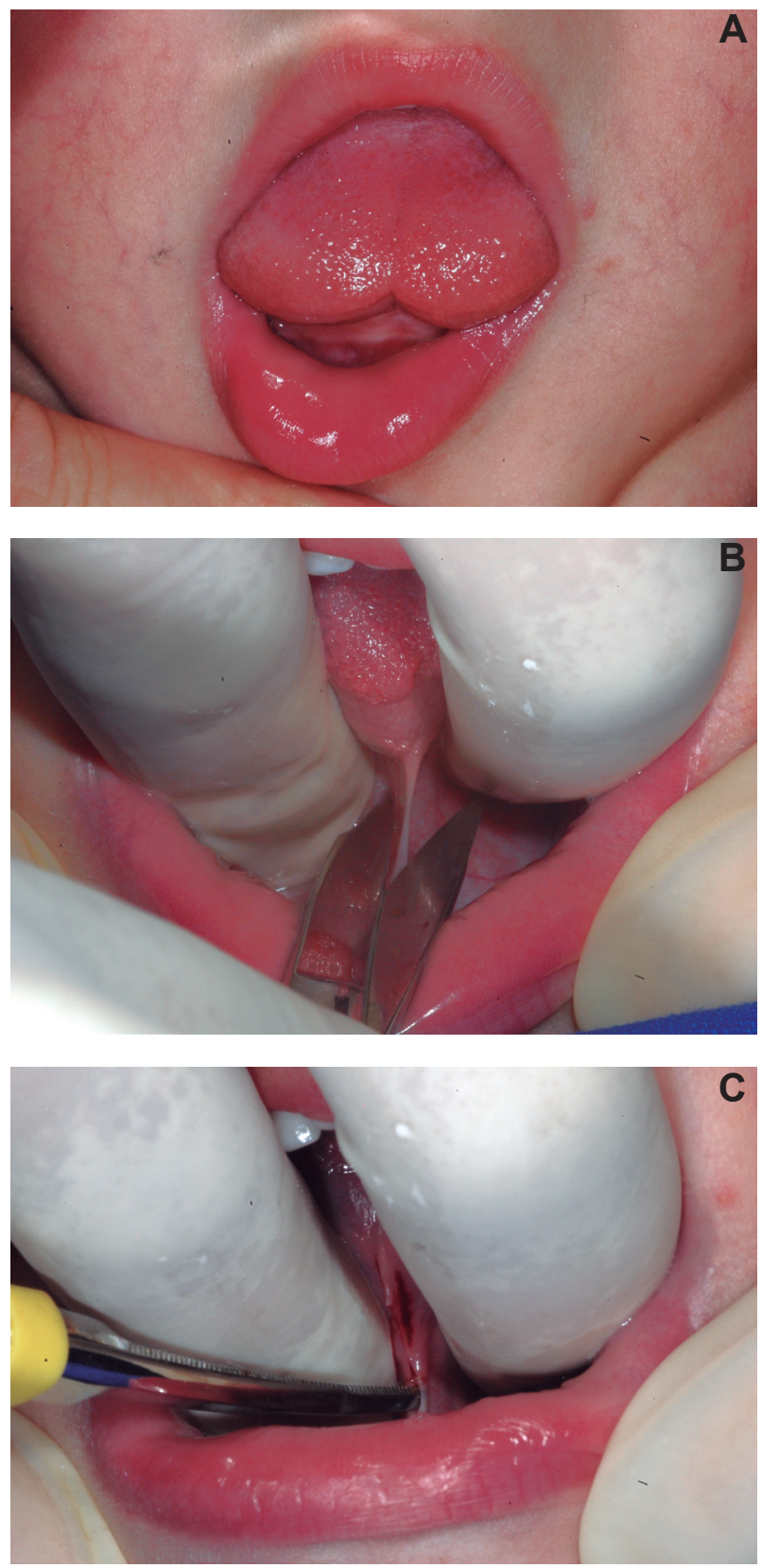

Figure 1- Frenotomy in a baby with ankyloglossia. A) Heart-shaped tongue during protrusion caused by a short lingual frenulum with anterior insertion. B) Tongue being held up towards the palate and scissors in position to cut the frenulum. C) Frenulum was cut through the white, fascia-like tissue along a line parallel with the tongue 

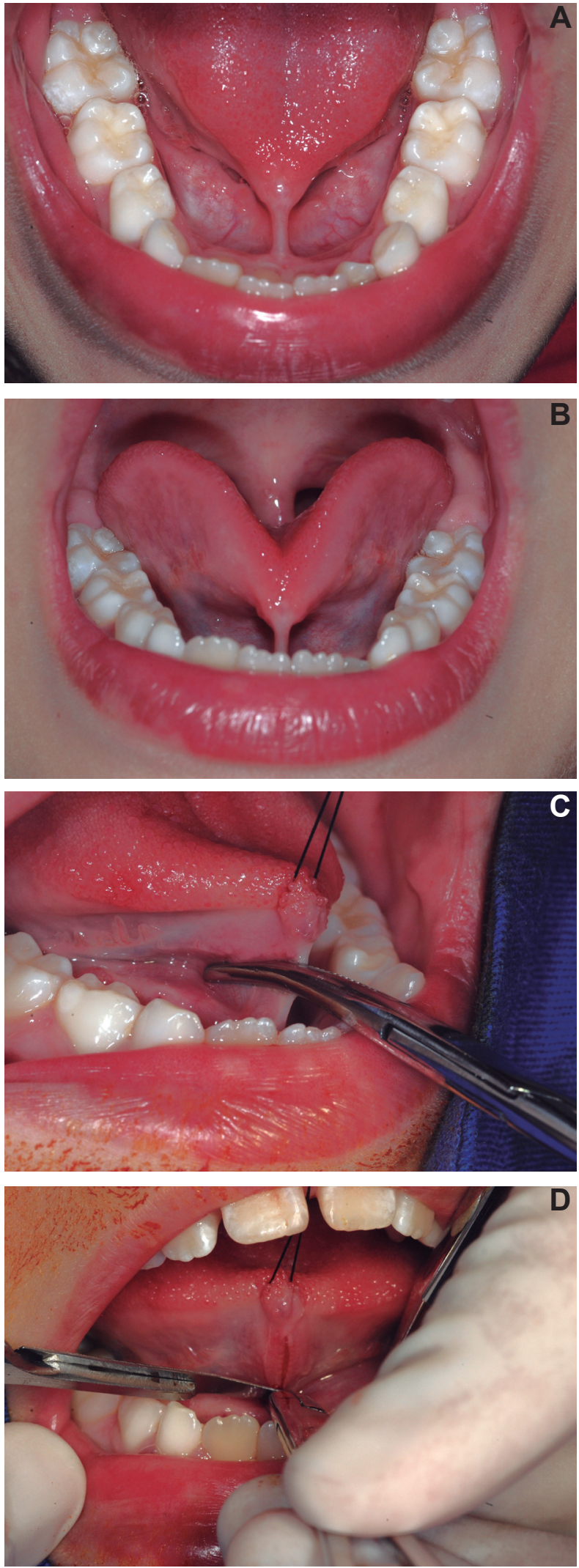
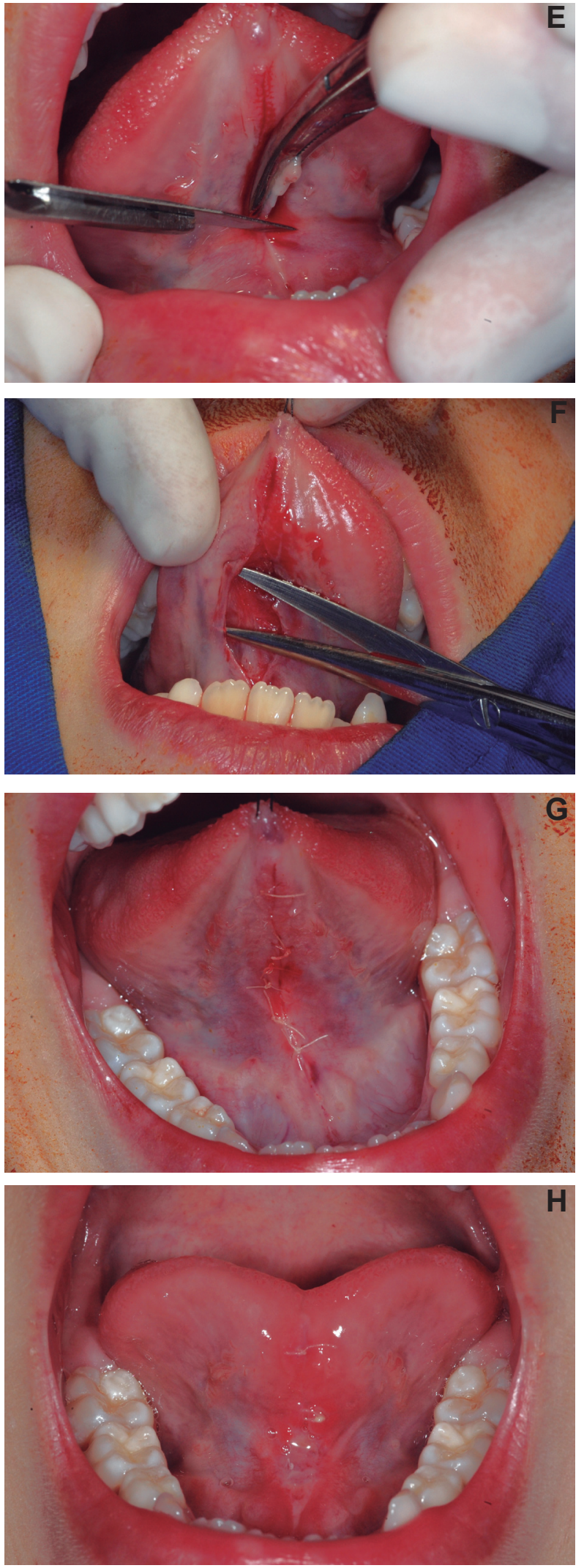

Figure 2- Frenectomy with use of one hemostat. A) Thick and short lingual frenulum with anterior insertion. B) Restricted central tongue tip elevation caused by abnormal attachment of the base of the tongue. C) Frenulum being held with a small curved hemostat with the convex curve facing the ventral surface of the tongue. D) First incision following the curvature of the hemostat, cutting through the upper aspect of the frenulum. E) Second incision at the lower aspect of the frenulum. F) Wound edges being dissected with the tips of blunt-ended scissors. G) Absorbable sutures placed over the wound. $H$ ) Clinical aspect of the surgical site on the seventh postoperative day 
made with a \#15c blade from the tip to the base of the tongue following the device (Fig. 4C and D). The grooved director was removed and a 3-0 silk suture was used for tongue traction. The frenulum remaining was excised (Fig. 4E) and the wound edges were dissected and sutured with 3-0 silk suture (Fig. 4F).

\section{Laser frenectomy}

A seven-year-old male was referred to the Clinic of Pediatric Dentistry by a speech therapist due to impaired speech caused by a short lingual frenulum
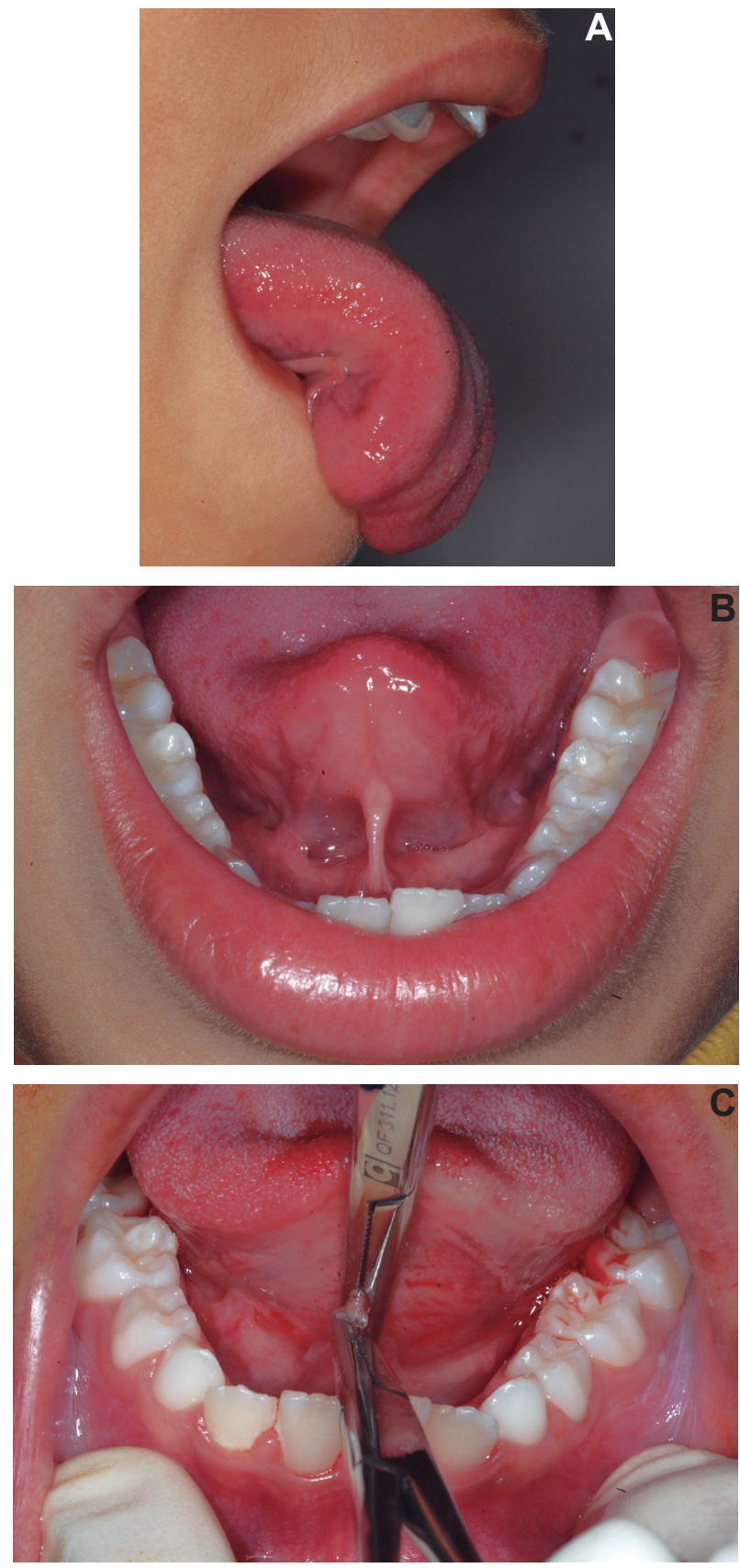

Figure 3- Frenectomy with use of two hemostats. A) Clinical aspect of the tongue during protrusion. B) Short and tight lingual frenulum. C) Frenulum held with two hemostats, with their tips meeting in the deep aspect near the base of the tongue. D) Excised triangular tissue held with the hemostats. E) Excision of fiber remnants. F) Silk sutures placed over the wound
(Fig. 5A). The extraoral and intraoral antisepsis, anesthesia of lingual nerve (Fig. 5B) and tongue traction were conducted as previously described. The frenulum incision was carried out with diode laser at a wavelength of $800 \mathrm{~nm}$ and power of $2 \mathrm{~W}$ in non-contact mode, which was applied continuously to the central area of the frenulum from the tip to the base of the tongue (Fig. 5C and D). Aspiration was not needed except for the vapor produced by diode laser during the cutting. Suture was not performed, and postoperative period was uneventful (Fig. 5E).
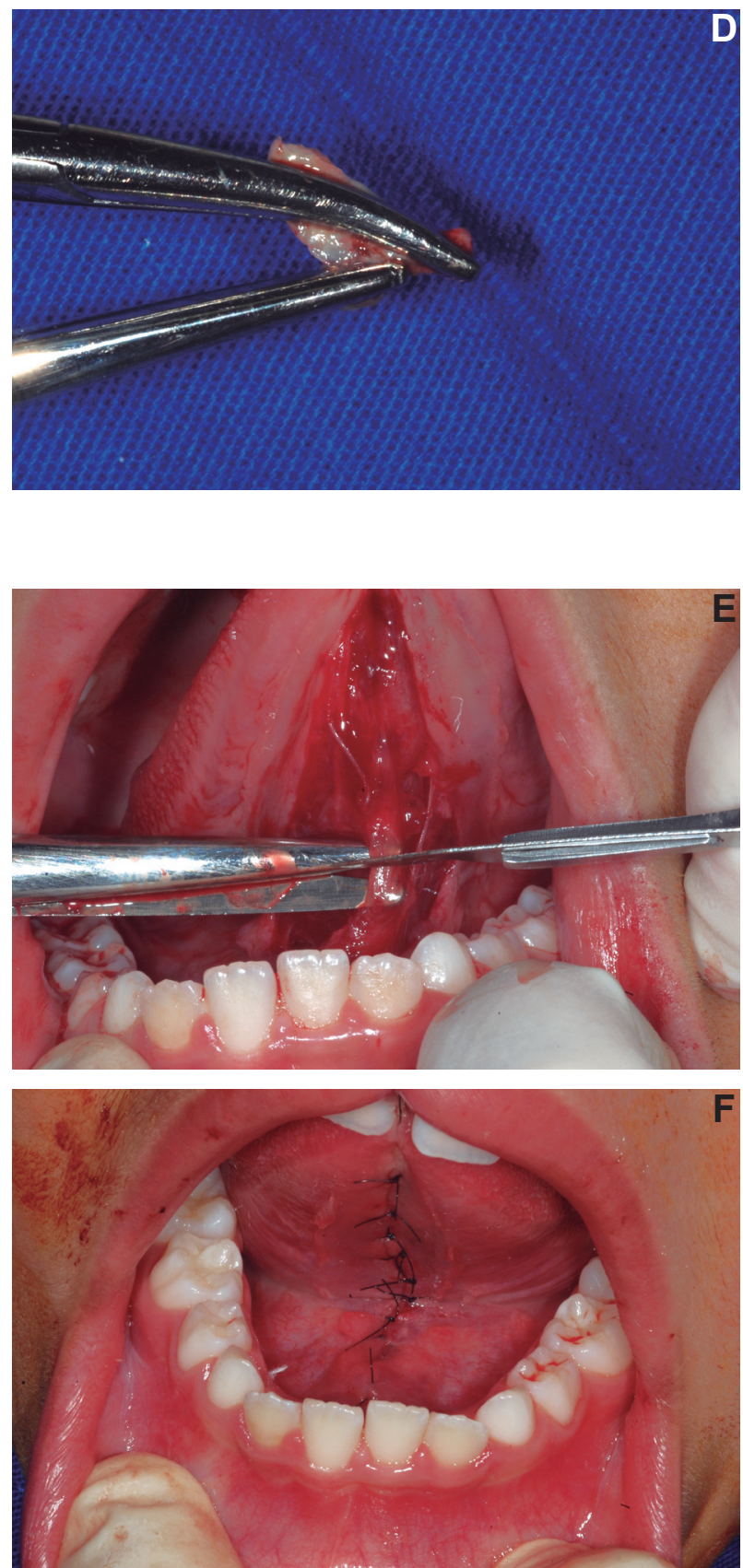

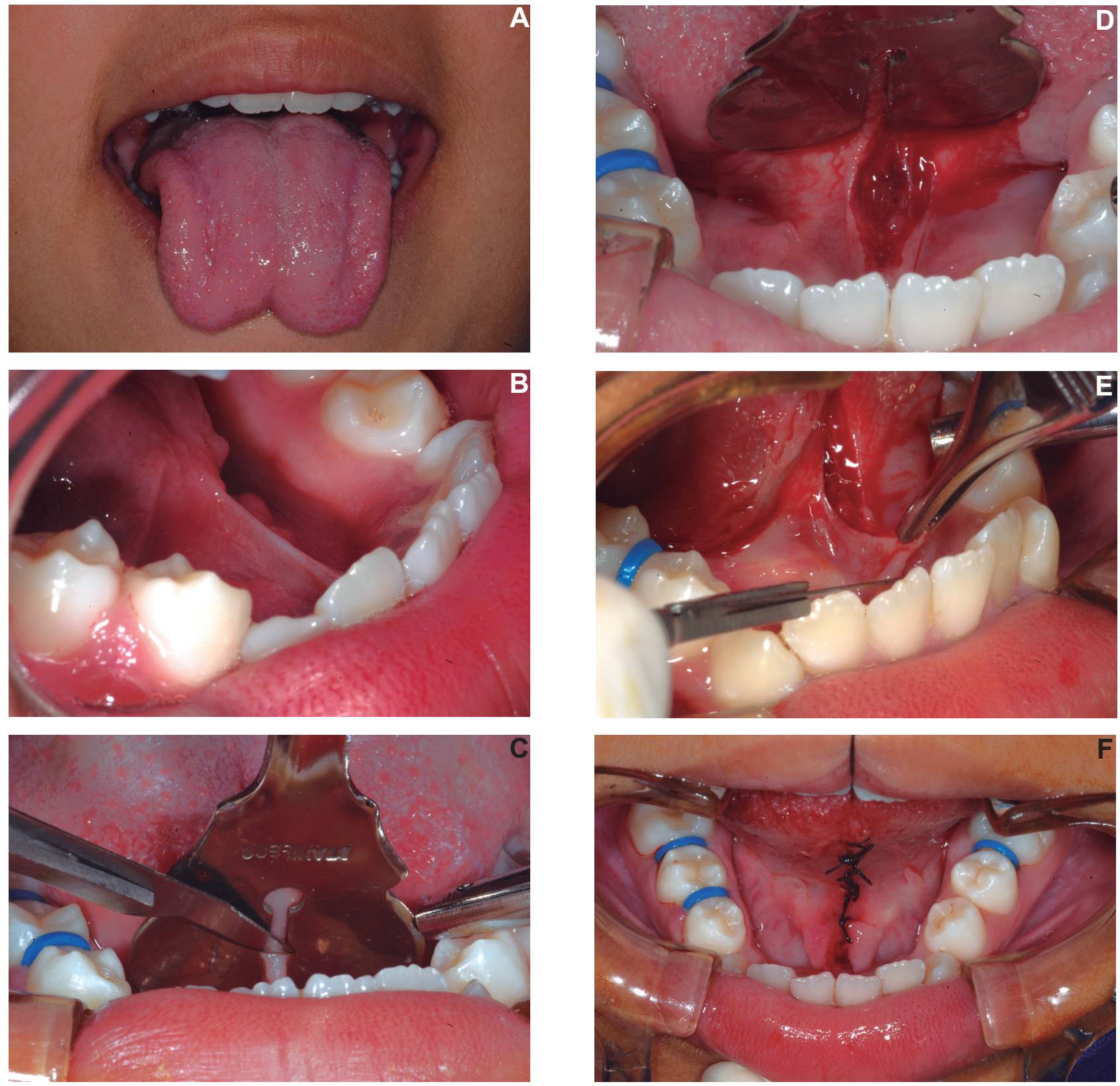

Figure 4- Frenectomy with use of a grooved director. A) Heart-shaped tongue during protrusion. B) Short lingual frenulum with apical insertion. C) Tongue being raised toward the palate with a grooved director. D) Incision from the tip to the base of the tongue following the grooved director. E) Excision of the remaining frenulum. F) Silk sutures placed over the wound

\section{DISCUSSION}

In the present work, a case series of children diagnosed with ankyloglossia and approached with different surgical techniques was presented. The choice of the technique was based on appropriate circumstances carefully evaluated preoperatively, which will be further discussed.

The exact cause of ankyloglossia is unknown, although it is likely to be due to abnormal development of the mucosa covering the anterior two-thirds of mobile tongue ${ }^{2}$. In most of cases, ankyloglossia is seen as an isolated finding in children. However, several syndromes are associated with this physical finding, including Ehlers-Danlos syndrome, Beckwith-Wiedemann syndrome, Simosa syndrome, $\mathrm{X}$-linked cleft palate and orofaciodigital syndrome $2,3,8,21,27$. Additionally, maternal cocaine use is reported to increase the risk of ankyloglossia to more than threefold ${ }^{2,21}$.

After the establishment of diagnosis of ankyloglossia in children, clinicians may struggle with the management of these patients, since there is no consensus on the indication, timing and type of surgical intervention. The examination of lingual frenulum should consider the morphological and functional aspects of the tongue. The indication of surgery for functional limitations due to 

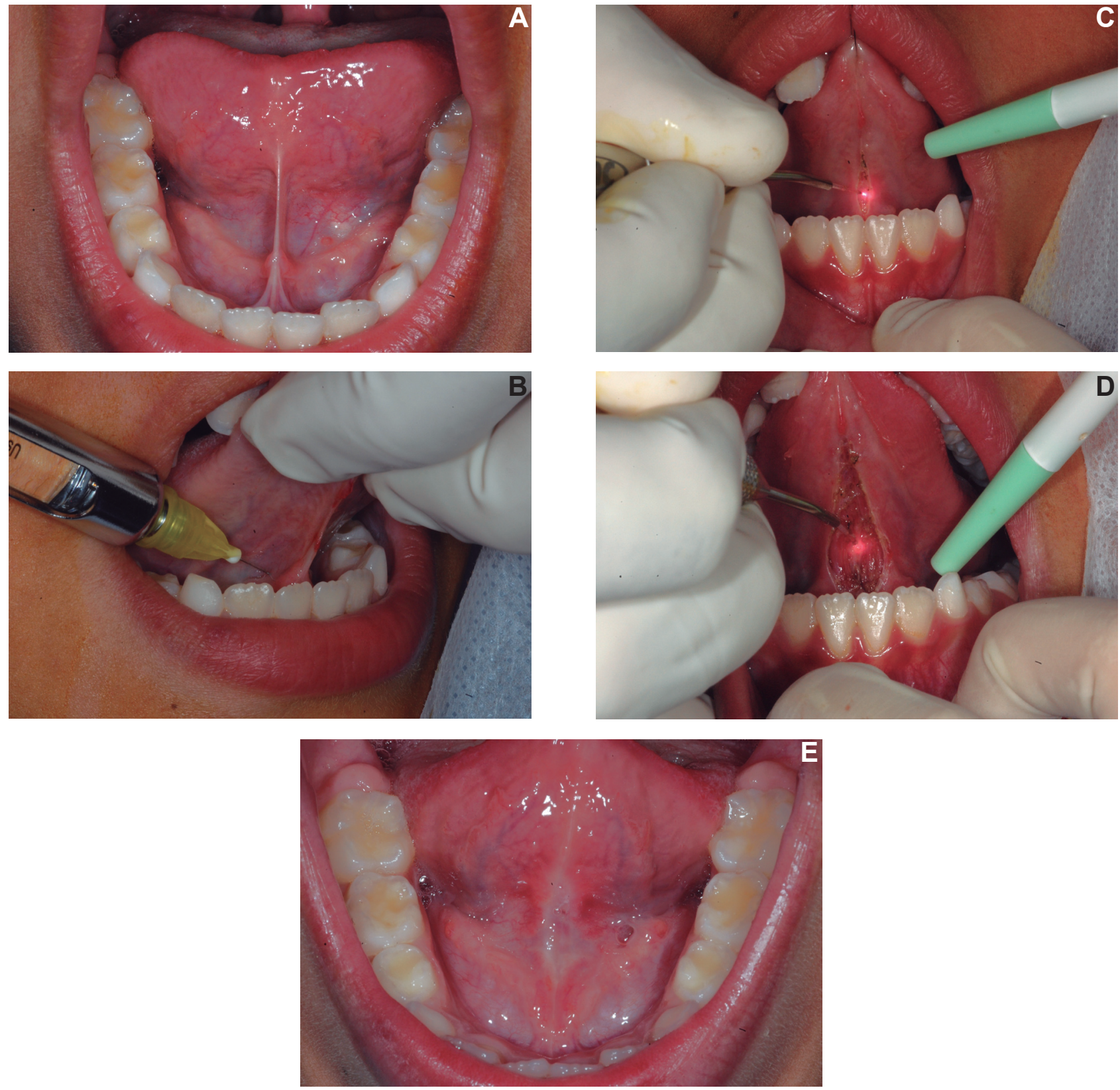

Figure 5- Laser frenectomy. A) Short lingual frenulum. B) Infiltrative anesthesia of the lingual nerve. C) Diode laser application to the central area of the frenulum. D) Laser application from the tip to the base of the tongue. E) Clinical aspect of the surgical site on the fourteenth postoperative day

ankyloglossia should occur if evaluation shows that function may be improved by surgery ${ }^{19}$.

Correct diagnosis of ankyloglossia and early intervention are imperative, since several consequences ranging from restriction of tongue movement to impairment of mandibular growth may occur. In nursing mothers, it may cause breastfeeding difficulties, poor milk transfer and nipple damage, resulting in early weaning and low weight gain in babies ${ }^{4,22,16}$. Speech articulation problems are the most common indications for lingual frenulum surgery in preschool children ${ }^{17,28}$.

Frenotomy (the clipping of the lingual frenulum) is the most indicated technique for babies with ankyloglossia since it is a conservative, simple and quick procedure that may be performed in the dental office settings during initial consultation ${ }^{12,24}$. Babies experience only minimal discomfort and can breastfeed immediately after the procedure, since the lingual frenulum is thin and with few blood vessels, resulting in very little bleeding after the cutting, as seen in the first case presented here. The limitation of this technique is the possibility of recurrence and the need to perform complementary procedures to release the tongue satisfactorily ${ }^{12,22,24}$.

Frenectomy corresponds to the complete excision of the frenulum. This procedure is more invasive and difficult to be performed in young 
children, although the results are more predictable, decreasing the recurrence rate ${ }^{18,22}$. There are no conclusive parameters regarding the timing of frenectomy in the literature ${ }^{22,30}$. However, surgery should be performed before the child develops abnormal swallowing and speech patterns. When the procedure is performed in older children, they should be referred to a speech therapist in order to reestablish the normal functions of the tongue 22 .

In the cases presented here, frenectomies were performed with the aid of different instruments and equipment, such as hemostats, grooved director and laser. The hemostats are used to delimit the area to be excised as well as to guide the incisions. When two hemostats are used, the risk of inadvertent soft tissue laceration is decreased, since the operator should only follow the hemostats with a blade to completely remove the tissue. Thus, clinicians who do not have broad experience in performing frenectomy in children may feel more confident when using two hemostats since the location of the incisions is previously determined. However, when the frenulum is too short, the use of two hemostats may not be feasible due to space limitation. Thus, only one hemostat clamped at the upper aspect of the frenulum may be helpful to guide the incision close to the ventral surface of the tongue. After the release of the tongue, care must be taken not to injury the submandibular ducts when making the second incision at the lower aspect of the frenulum.

The grooved director allows firm control of the tongue during anesthesia and serves as a guide for the incision at the upper aspect of the frenulum. However, frenectomy using the grooved director does not eliminate the need for tongue traction with a silk suture in order to stabilize the tongue during dissection and suture of the wound.

Laser technology has been considered as an alternative to the conventional techniques, presenting several advantages such as: shorter operative working time, tissue cauterization and sterilization, hemostasis, less local anesthesia requirement, and fewer postoperative complications (pain, swelling and infection) ${ }^{15}$. Laser also enhances access and visualization due to the lack of interposed instruments and bleeding at the operative field. Additionally, the need for suture is eliminated and a uniform depth in the surgical site is maintained, reducing unnecessary damage to tongue muscle $e^{1,15,29}$. For all these features, laser is well tolerated by children.

It is worth mentioning that all the patients were referred to a speech therapist to have their tongue movement and speech articulation improved, and were followed up for over two years after treatment in our clinic.

\section{CONCLUSION}

All the techniques presented are successful for the treatment of ankyloglossia and require a skilled professional. Laser may be considered a simple and safe alternative for children while reducing the amount of local anesthetics, the bleeding and the chances of infection, swelling and discomfort.

\section{REFERENCES}

1- Aras MH, Göregen M, Güngörmüş M, Akgül HM. Comparison of diode laser and Er:YAG lasers in the treatment of ankyloglossia. Photomed Laser Surg. 2010;28(2):173-7.

2- Chu MW, Bloom DC. Posterior ankyloglossia: a case report. Int J Pediatr Otorhinolaryngol. 2009;73(6):881-3.

3- De Felice C, Toti P, Di Maggio G, Parrini S, Bagnoli F. Absence of the inferior labial and lingual frenula in Ehlers-Danlos syndrome. Lancet. 2001;357(9267):1500-2.

4- Dollberg S, Botzer E, Grunis E, Mimouni FB. Immediate nipple pain relief after frenotomy in breast-fed infants with ankyloglossia: a randomized, prospective study. J Pediatr Surg. 2006;41(9): 1598-600.

5- Fleiss PM, Burger M, Ramkumar H, Carrington P. Ankyloglossia: a cause of breastfeeding problems? J Hum Lact. 1990;6(3):128-9. 6- Friend GW, Harris EF, Mincer HH, Fong TL, Carruth KR. Oral anomalies in the neonate, by race and gender, in an urban setting. Pediatr Dent. 1990;12(3):157-61.

7- Griffiths DM. Do tongue ties affect breastfeeding? J Hum Lact. 2004;20(4):409-14.

8- Hall WA. To clip or not to clip, that is the question? World Neurosurg. 2012;77(2):291-2.

9- Harris EF, Friend GW, Tolley E. Enhanced prevalence of ankyloglossia with maternal cocaine use. Cleft Palate Craniofac J. $1992 ; 29(1): 72-6$.

10- Heller J, Gabbay J, O'Hara C, Heller M, Bradley JP. Improved ankyloglossia correction with four-flap Z-frenuloplasty. Ann Plast Surg. 2005;54(6):623-8.

11- Hogan M, Westcott C, Griffiths M. Randomized, controlled trial of division of tongue-tie in infants with feeding problems. J Paediatr Child Health. 2005;41(5/6):246-50.

12- Hong P, Lago D, Seargeant J, Pellman L, Magit AE, Pransky SM. Defining ankyloglossia: a case series of anterior and posterior tongue ties. Int J Pediatr Otorhinolaryngol. 2010;74(9):1003-6. 13- Horton CE, Crawford HH, Adamson JE, Ashbell TS. Tongue-tie. Cleft Palate J. 1969;6:8-23.

14- Jorgenson RJ, Shapiro SD, Salinas CF, Levin LS. Intraoral findings and anomalies in neonates. Pediatrics. 1982;69(5):57782.

15- Kara C. Evaluation of patient perceptions of frenectomy: a comparison of Nd:YAG laser and conventional techniques. Photomed Laser Surg. 2008;26(2):147-52.

16- Karabulut R, Sönmez K, Türkyilmaz Z, Demiroğullari B, Ozen IO, Bağbanci B, et al. Ankyloglossia and effects on breast-feeding, speech problems and mechanical/social issues in children. B-ENT. 2008;4(2):81-5.

17- Klockars T, Pitkäranta A. Pediatric tongue-tie division: indications, techniques and patient satisfaction. Int J Pediatr Otorhinolaryngol. 2009;73(10):1399-401.

18- Kupietzky A, Botzer E. Ankyloglossia in the infant and young child: clinical suggestions for diagnosis and management. Pediatr Dent. 2005;27(1):40-6.

19- Lalakea L, Messner A. Frenotomy and frenuloplasty: if, when and how. Oper Tech Otolaryngol Head Neck Surg. 2002;13(1):937. 
20- Lau JT, Ong GB. A grooved table-spoon for tongue-tie release and hernial neck transfixion. Aust NZ J Surg. 1983;53(1):61-2. 21- Mabu HM. Surgical management of Ankyloglossia: a case report. Int J Contemp Dent. 2010;1(2):58-61.

22- Manfro AR, Manfro R, Bortoluzzi MC. Surgical treatment of ankyloglossia in babies: case report. Int J Oral Maxillofac Surg. 2010;39(11):1130-2.

23- Marmet C, Shell E, Marmet R. Neonatal frenotomy may be necessary to correct breastfeeding problems. J Hum Lact. $1990 ; 6(3): 117-21$.

24- Masaitis NS, Kaempf JW. Developing a frenotomy policy at one medical center: a case study approach. J Hum Lact. 1996;12(3):229-32.

25- Messner AH, Lalakea ML, Aby J, Macmahon J, Bair E. Ankyloglossia: incidence and associated feeding difficulties. Arch Otolaryngol Head Neck Surg. 2000;126(1):36-9.

26- Messner AH, Lalakea ML. Ankyloglossia: controversies in management. Int J Pediatr Otorhinolaryngol. 2000;54(2/3):12331.
27- Moore GE, Ivens A, Chambers J, Farrall M, Williamson R, Page $D C$, et al. Linkage of an X-chromosome cleft palate gene. Nature. 1987;326(6108):91-2.

28- Olivi G, Signore A, Olivi M, Genovese MD. Lingual frenectomy: functional evaluation and new therapeutical approach. Eur J Paediatr Dent. 2012;13:101-6.

29- Puthussery FJ, Shekar K, Gulati A, Downie IP. Use of carbon dioxide laser in lingual frenectomy. $\mathrm{Br} \mathrm{J}$ Oral Maxillofac Surg. 2011;49(7):580-1.

30- Segal LM, Stephenson R, Dawes M, Feldman P. Prevalence, diagnosis, and treatment of ankyloglossia: methodologic review. Can Fam Physician. 2007;53(6):1027-33.

31- Suter VG, Bornstein MM. Ankyloglossia: facts and myths in diagnosis and treatment. J Periodontol. 2009;80(8):1204-19. 